\title{
AN ACTUALIST'S GUIDE TO QUANTIFYING IN
}

Agustín Rayo

Massachusetts Institute of Technology

arayo@mit.edu

SUMMARY: I develop a device for simulating quantification over merely possible objects from the perspective of a modal actualist — someone who thinks that everything that exists actually exists.

KEY WORDS: intentional identity, empty names, possible worlds, merely possible objects, modal actualism

RESUMEN: Desarrollo un método para simular cuantificación sobre objetos meramente posibles. El método es aceptable desde la perspectiva de un actualista modal.

PALABRAS CLAVE: identidad intencional, nombres vacíos, mundos posibles, objetos meramente posibles, actualismo modal

\section{Introduction}

Philosophers call on possible worlds to perform different kinds of jobs. One of these jobs is that of explaining what the truth of modal truths and the falsity of modal falsities consists in. "What does the possibility that $p$ consist in?", you ask. "It consists in the existence of a possible world at which $p$ ", someone might reply.

Possible worlds are also used as semantic machinery. The semanticist needs entities for her quantifiers to range over, and possible worlds - or, more generally, possibilia - can be used to construct them. One might take a proposition to be a set of possible worlds (structured or not); one might take the intension of a predicate to be a function that assigns each world a set of objects in that world (or some complication thereof); one might use possible worlds to characterize the semantic values of modal operators; and so forth.

(It is sometimes assumed that these two jobs are best performed by a single notion of possible world, as in Lewis 1986. But it is worth keeping in mind that such an assumption is not mandated. It would in principle be possible to develop two distinct notions of possible world, one for the foundationalist project and another for the semantic project.)

The main objective of this paper is to defend the claim that a specialized modal ontology is not needed as semantic machinery. (The further claim that it is not needed to explain what modal truth consists in is defended in chapters 2 and 5 of Rayo forthcoming.) 
Some philosophers might be interested in this sort of project because of ontological scruples. Not me: my own view is that ontology is cheap. I am interested in the project because I think it helps clarify the role of possible worlds in our philosophical theorizing.

My proposal is an instance of what David Lewis called "ersatzism". I will argue that the needs of the semanticist can be fulfilled by using representatives for possibilia in place of possibilia. Although there are other ersatzist proposals in the literature, ${ }^{1} \mathrm{I}$ hope the machinery developed here will earn its keep by delivering an attractive combination of frugality and strength.

The proposal is frugal in two different respects. First, it is metaphysically frugal: it is designed to be acceptable to modal actualists, and presupposes very little by way of ontology. (I help myself to settheory, but do not assume a specialized modal ontology, or an ontology of properties.) Second, the proposal is ideologically frugal: it does not presuppose potentially controversial expressive resources such as infinitary languages or non-standard modal operators. The point of developing machinery that presupposes so little is that philosophers of different persuations can put it to work without having to take a stance on difficult philosophical issues.

As far as strength is concerned, one gets a qualified version of the following claim: anything that can be said by quantifying over Lewisian possibilia can also be said by using the machinery developed here. The result is that the proposal can be used quite freely in the context of semantic theorizing, without having to worry too much about running into expressive limitations. An especially useful feature of the proposal is that it allows one to enjoy the benefits of quantification over sets of possibilia, which are often appealed to in the course of semantic theorizing. ${ }^{2}$

\footnotetext{
${ }^{1}$ See, for instance, Plantinga 1976, and chapter 3 of Lewis 1986. A recent ersatzist proposal is discussed in Fine 2002 and Sider 2002 (but embraced only by Sider). The sort of proposal that Fine and Sider discuss has a more ambitious objective than the proposal developed here, since it is intended to capture finer-grained distinctions amongst possibilities. It also relies on more substantial expressive and ontological resources. (It relies, in particular, on an infinitary language and an ontology of properties.)

${ }^{2}$ By emulating the benefits of quantification over sets of possibilia the proposal also allows us to go some way towards addressing the expressive limitations identified in chapter 7 of Williamson 2010. In particular, one can use the dot-notation introduced in section 6 to express a version of the claim that incompossible objects form a set:
}

$$
\exists \alpha \exists x \exists y(\alpha=\{x, y\} \wedge \diamond(\exists z(z=\dot{x})) \wedge \diamond(\exists z(z=\dot{y})) \wedge \neg \diamond(\exists z \exists v(z=\dot{x} \wedge v=\dot{y}))) .
$$


Possible-worlds-theorists sometimes claim that the same individual exists according to distinct possible worlds. (There is a world according to which I have a sister who is a philosopher, and a world at which that very individual is a cellist rather than a philosopher.) Ersatzist representatives for such worlds might be said to be linked. Much of the paper will be devoted to the phenomenon of linking. An effective treatment of linking is crucial to the success of the ersazist program.

\section{Possibility}

Sadly, I don't have a sister. But I might have had a sister. In fact, I might have had a sister who was a philosopher. And, of course, had I had a sister who was a philosopher, she wouldn't have been a philosopher essentially: she might have been a cellist instead. The following is therefore true: ${ }^{3}$

SISTER

$\diamond(\exists x(\operatorname{Sister}(x, \mathrm{AR}) \wedge \operatorname{Phil}(x) \wedge \diamond(\operatorname{Cellist}(x) \wedge \neg \operatorname{Phil}(x))))$

(Read: I might have had a sister who was a philosopher and might have been a cellist rather than a philosopher.)

On the most straightforward possible-worlds semantics for first-order modal languages, SISTER will only be counted as true if there are worlds $w_{1}$ and $w_{2}$ with the following properties: according to $w_{1}$, there is an individual who is my sister and a philosopher; according to $w_{2}$, that very individual - as one is inclined to put it - is a cellist rather than a philosopher. It is therefore tempting to say the following:

$$
\exists x\left([\operatorname{Sister}(x, \operatorname{AR}) \wedge \operatorname{Phil}(x)]_{w_{1}} \wedge[\operatorname{Cellist}(x) \wedge \neg \operatorname{Phil}(x)]_{w_{2}}\right)
$$

(Read: There is an $x$ such that: $(i)$ according to $w_{1}, x$ is my sister and a philosopher, and (ii) according to $w_{2}, x$ is a cellist rather than a philosopher.)

But is there anything to make this existential quantification true? A merely possible sister could do the job. But modal actualists believe there is no such thing. The job could also be done by an actually existing object who is not my sister but might have been my sister. (See Williamson 2010.) But the claim that such objects exist would

\footnotetext{
${ }^{3}$ See McMichael 1983.
} 
be a substantial metaphysical assumption -an assumption that it would be best to avoid, if at all possible.

\section{A Kripke-Semantics for Actualists}

There is a certain sense in which it is straightforward for an actualist to give an adequate Kripke-semantics for modal sentences. The trick is to have one's semantics quantify over representations of possibilities, rather than over the possibilities themselves. In this section I will describe one such semantics. It is an elaboration of an idea introduced in Roy 1995 and further developed in Melia 2001.

Let $L$ be a first-order language, and let $L^{\diamond}$ be the result of enriching $L$ with the sentential operator " $\diamond$ ". An $a$-world (short for "actualist-world") for $L^{\diamond}$ is an ordered pair $\langle D, I\rangle$, consisting of a domain and an interpretation function, such that:

- The domain $D$ is a set containing two kinds of entities. First, it contains every ordered pair of the form $\langle x$, "actual" $\rangle$, for $x$ an individual in the domain of $L$. (These pairs will be used to represent actually existing objects.) Second, it may contain ordered pairs of the form $\langle x$, "nonactual" $\rangle$, where $x$ is some actually existing individual, set-theoretic or otherwise. (These pairs will be used to represent merely possible objects.)

- If $\mathrm{C}$ is an individual constant of $L$ and $x$ is its intended interpretation, the interpretation-function $I$ assigns the pair $\langle x$, "actual" $\rangle$ to C. (Accordingly, if "SocRATES" is an individual constant referring to Socrates, $I$ assigns the pair 〈Socrates, "actual") to "SOcRATES".)

- $I$ assigns a subset of $D^{n}$ to each $n$-place predicate-letter of $L$, and a function from $D^{n}$ to $D$ to each $n$-place function-letter of $L$.

The notions of truth and satisfaction at an $a$-world are characterized along standard lines, with the proviso that " $x=x$ " is only satisfied at an $a$-world by objects in the domain of that $a$-world, with the result that " $x=x$ " can be used as an existence predicate. See Appendix A for details.

The best way to see how $a$-worlds are supposed to work is by considering a simple example. Take the $a$-world $\left\langle D_{1}, I_{1}\right\rangle$ from figure 1. The domain of $\left\langle D_{1}, I_{1}\right\rangle$ consists of the pairs 〈Agustín, "actual" $\rangle$ (which represents me) and 〈Socrates, "nonactual"〉 (which represents not Socrates, but a merely possible object), and $I_{1}$ assigns "Sister" a 
set containing the pair $\langle\langle$ Socrates, "nonactual" $\rangle,\langle$ Agustín, "actual" $\rangle\rangle$. The result is that $\left\langle D_{1}, I_{1}\right\rangle$ makes " $\exists x(\operatorname{Sister}(x, \mathrm{AR}))$ " true, and therefore represents a possibility whereby I have a sister. (Why use the pair 〈Socrates, "nonactual"〉 to represent my merely possible sister rather than some other pair - 〈Plato, "nonactual" $\rangle$, say? No good reason. Just like one can write a story according to which I have a sister using any font one likes, so one can define an $a$-world according to which I have a sister using any pair $\langle z$, "nonactual" $\rangle$ one likes.)

It is useful to compare $a$-worlds to Lewisian worlds. Like $a$-worlds, Lewisian worlds can be thought of as representing possibilities. Here is Lewis:

How does a world, [Lewisian] or ersatz, represent, concerning Humphrey, that he exists? [...] A [Lewisian] world might do it by having Humphrey himself as a part. That is how our own world represents, concerning Humphrey, that he exists. But for other worlds to represent in the same way that Humphrey exists, Humphrey would have to be a common part of many overlapping worlds [... ]. I reject such overlap $[\ldots]$. There is a better way for a [Lewisian] world to represent, concerning Humphrey, that he exists [...] it can have [...] a Humphrey of its own, a flesh-and-blood counterpart of our Humphrey, a man very much like Humphrey in his origins, in his intrinsic character, or in his historical role. By having such a part, a world represents de re, concerning Humphrey — that is, the Humphrey of our world, whom we as his worldmates may call simply Humphrey - that he exists and does thus-and-so. ${ }^{4}$

(It is easy to lose track of Lewis's representationalism because he also subscribed to a different claim: what it is for it to be possible that $p$ is for there to be a Lewisian world at which (i.e. representing that) $p$. For further discussion of these issues, see Rayo forthcoming.)

Whereas Lewisian worlds represent by analogy, $a$-worlds represent by satisfaction. A Lewisian world represents the possibility that I have a sister by containing a person who is similar to me in certain respects, and has a sister. An $a$-world, on the other hand, represents the possibility that I have a sister by being such as to satisfy the formula " $\exists x(\operatorname{Sister}(x, \mathrm{AR}))$ ".

From the perspective of the Lewisian, an individual with a counterpart in the actual world represents its actual-word counterpart,

${ }^{4}$ Lewis 1986, p. 194. (Lewis writes "genuine" where I have substituted "Lewisian".) Lewis takes the counterpart relation to be context-dependent, but here I shall treat it as constant for the sake of simplicity. Also for the sake of simplicity, I shall assume that the counterpart relation is an equivalence. 
and an individual with no counterpart in the actual world represents a merely possible object. From the present perspective, a pair of the form " $\langle x$, "actual' $\rangle$ " represents its first component, and a pair of the form " $\langle x$, "nonactual' $\rangle$ " represents a merely possible object (even though the pair itself, and both of its components, are actually existing objects).

Two representations are linked if - as one is inclined to put itthey concern the same individual, even if the individual in question doesn't exist. In order for a Kripke semantics based on $a$-worlds to verify SISTER, there must be linking amongst $a$-worlds. In particular, some $a$-world must represent a possibility whereby I have a sister who is a philosopher and another must represent a possibility whereby - as one is inclined to put it - that very same individual is a cellist rather than a philosopher.

Let us first see how linking gets addressed from a Lewisian perspective. $l_{1}$ and $l_{2}$ are Lewisian worlds: $l_{1}$ contains an individual $a_{1}$ who bears the right sort of similarity to me and an individual $s_{1}$ who is $a_{1}$ 's sister and a philosopher; $l_{2}$ contains an individual $s_{2}$ who is a cellist. Accordingly, $l_{1}$ represents a possibility whereby my sister is a philosopher, and $l_{2}$ represents a possibility whereby someone is a cellist. But nothing so far guarantees linking. Nothing so far guarantees that - as one is inclined to put it - the individual $l_{1}$ represents as my sister is the very individual that $l_{2}$ represents as a cellist. What is needed for linking is that $s_{1}$ and $s_{2}$ be counterparts: that they be similar in the right sorts of respects.

The same maneuver can be used when it comes to $a$-worlds. Like the Lewisian, we shall use counterparthood amongst representations to capture linking. For Lewis, representations are counterparts just in case they are similar in the right sorts of respects. From the present perspective, we shall say that representations are counterparts just in case they are identical (though other ways of defining the counterpart relation could be used as well). Here is an example. The $a$-world $\left\langle D_{1}, I_{1}\right\rangle$ represents a possibility whereby I have a sister who is a philosopher. Now consider $a$-worlds $\left\langle D_{2}, I_{2}\right\rangle$ and $\left\langle D_{3}, I_{3}\right\rangle$ from table 1 (p. 9). Each of them represents a possibility whereby someone is a cellist rather than a philosopher. But only $\left\langle D_{2}, I_{2}\right\rangle$ is linked to $\left\langle D_{1}, I_{1}\right\rangle$. For $\left\langle D_{1}, I_{1}\right\rangle$ and $\left\langle D_{2}, I_{2}\right\rangle$ both employ 〈Socrates, "nonactual" $\rangle$ as a representation, and it is this that guarantees that - as one is inclined to put it - the individual who $\left\langle D_{1}, I_{1}\right\rangle$ represents as my sister is the very individual that $\left\langle D_{2}, I_{2}\right\rangle$ represents as a cellist. On the other hand, since $\left\langle D_{3}, I_{3}\right\rangle$ represents a possibility 
$\left\langle D_{1}, I_{1}\right\rangle$

$D_{1}=\{\langle$ Agustín, "actual" $\rangle,\langle$ Socrates, "nonactual" $\rangle\}$

$I_{1}$ ("Philosopher") $=\{\langle$ Socrates, "nonactual" $\rangle\}$

$I_{1}($ "Cellist") $=\{\}$

$I_{1}($ "Sister") $=\{\langle\langle$ Socrates, "nonactual" $\rangle,\langle$ Agustín, "actual" $\rangle\rangle\}$

$I_{1}($ "AR") $=\langle$ Agustín, "actual" $\rangle$

$\left\langle D_{2}, I_{2}\right\rangle$

$D_{2}=\{\langle$ Socrates, "nonactual" $\rangle\}$

$I_{2}$ ("Philosopher") $=\{\}$

$I_{2}($ "Cellist" $)=\{\langle$ Socrates, "nonactual" $\rangle\}$

$I_{2}($ "Sister") $=\{\}$

$I_{2}($ "AR") $=\langle$ Agustín, "actual" $\rangle$

$\left\langle D_{3}, I_{3}\right\rangle$

$D_{3}=\{\langle$ Plato, "nonactual" $\rangle\}$

$I_{3}$ ("Philosopher") $=\{\}$

$I_{3}($ "Cellist") $=\{\langle$ Plato, "nonactual" $\rangle\}$

$I_{3}($ "Sister") $=\{\}$

$I_{3}($ "AR") $=\langle$ Agustín, "actual" $\rangle$

$\left\langle D_{4}, I_{4}\right\rangle$

$D_{4}=\{\langle$ Agustín, "actual" $\rangle,\langle$ Plato, "nonactual" $\rangle\}$

$I_{4}($ "Philosopher") $=\{\langle$ Plato, "nonactual" $\rangle\}$

$I_{4}($ "Cellist") $=\{\}$

$I_{4}($ "Sister") $=\{\langle\langle$ Plato, "nonactual" $\rangle,\langle$ Agustín, "actual" $\rangle\rangle\}$

$I_{4}($ "AR") $=\langle$ Agustín, "actual" $\rangle$

These examples assume that the only non-logical expressions in $L$ are "Philosopher", "Cellist", "Sister" and "AR", and that the domain of $L$ is $\{$ Agustín $\}$.

Table 1: Examples of $A$-worlds 
whereby someone is a cellist by using 〈Plato, "nonactual") rather than 〈Socrates, "nonactual" $\rangle$, what one gets is that -as one is inclined to put it - the individual who $\left\langle D_{1}, I_{1}\right\rangle$ represents as my sister is distinct from the individual that $\left\langle D_{2}, I_{2}\right\rangle$ represents as a cellist.

It is important to keep in mind that an $a$-worlds-semantics is not a way of improving on the informal characterization of linking that I supplied a few paragraphs back. (Representations are linked if - as one is inclined to put it - they concern the same individual, even if the individual in question doesn't exist.) In particular, it is not a way of dispensing with the qualifying phrase "as one is inclined to put it". ${ }^{5}$ What an $a$-worlds-semantics delivers is an (actualistically acceptable) device for representing possibilities, which enjoys the following feature: it is clear when two representations are to be counted as linked. The reason this is helpful is that, as we shall see below, much of the theoretical work that can be carried out by quantifying over possibilities can be carried out by quantifying over representations of possibilities instead. So an $a$-worlds-semantics puts the actualist in a position to get on with certain kinds of theoretical work without having to worry about giving a proper characterization of linking.

\section{Admissibility}

There are $a$-worlds according to which someone is a married bachelor, and $a$-worlds according to which there might have been a human who wasn't essentially human. Such representations need to be excluded from our semantics, on pain of getting the result that sentences like $" \diamond(\exists x(\operatorname{Married}(x) \wedge \operatorname{Bachelor}(x))) "$ and " $\diamond(\exists x(\operatorname{Human}(x) \wedge \diamond(\exists y(y=$ $x \wedge \neg \operatorname{Human}(x))))) "$ are true. What we need is a notion of admissibility. Armed with such a notion, one can say that $\ulcorner\diamond \phi\urcorner$ is true just in case $\phi$ is true at some admissible $a$-world, and that $\ulcorner\square \phi\urcorner$ is true just in case $\phi$ is true at every admissible $a$-world. ${ }^{6}$

It is important to keep in mind the distinction between the semantic project of developing a Kripke-semantics for modal languages, on

${ }^{5}$ It is worth emphasizing that by availing oneself of an ontology of Lewisian worlds and a Lewisian counterpart relation one does not immediately do any better. What one gets is a way of making clear when two Lewisian worlds are to be counted as linked, not a characterization of linking. A friend of the Lewisian ontology can, however, give a proper characterization of linking by making an additional reductionist claim; namely, that there is no more to possibility than the existence of the relevant representation. There is, for example, no more to the fact that I might have had a sister than the fact that someone who is like me in certain respects has a sister.

${ }^{6} \mathrm{I}$ assume, for simplicity, that the accessibility relation is trivial. 
the one hand, and the project of accounting for the limits of metaphysical possibility, on the other. A semantics based on $a$-worlds is meant to address the former, but not the latter of these projects. Accordingly, the notion of admissibility that is presupposed by the semantic project should be thought of as a placeholder for whatever limits on the metaphysically possible turn out to be uncovered by a separate investigation. (On reasonable assumptions, one can show that a suitable notion of admissibility is guaranteed to exist wherever the limits turn out to lie. $)^{7}$ A semantics based on $a$-worlds is compatible with different views about how to fix the limits of metaphysical possibility. One might appeal to a Principle of Recombination, for example, or to a set of "basic modal truths". (My own account is spelled out in chapters 2 and 5 of Rayo forthcoming.)

Even if one appeals to an ontology of possible worlds in fixing the limits of metaphysical possibility, one might have good reasons for using $a$-worlds rather than possible worlds for the purposes of semantic theorizing. The easiest way to see this is by distinguishing between sparse and abundant conceptions of possible worlds. ${ }^{9}$ A sparse conception countenances worlds according to which there are objects that don't actually exist, but not worlds according to which it is true of specific non-existent objects that they exist. There is,

${ }^{7}$ More precisely, what one can show is this: provided there is a determinate fact of the matter about which sentences of $L^{\diamond}$ are true, there is a notion of admissibility relative to which an $a$-worlds semantics assigns the right truth-value to every sentence in $L^{\diamond}$. (I assume that the first-order language $L$ on which $L^{\diamond}$ is based has a set-sized domain, and a name for every object in this domain.) Proof: Where $S$ is the set of true sentences in $L^{\diamond}$, use Kripke's completeness theorem for modal languages to construct a Kripke-model for $S$ in which the domain consists of equivalence-classes of terms. Then transform the Kripke-model into an $a$-world semantics by substituting the pair $\langle x$, "actual" $\rangle$ for each object $x$ in the domain of the actual world of the Kripke-semantics containing a name for $x$, and the pair $\langle x$, "nonactual" $\rangle$ for each object $x$ in the domain of some non-actual world of the Kripke-semantics but not in the domain of the actual world of the Kripke-semantics. (The proof relies on the reasonable assumption that $S$ is consistent relative to a normal logic. To avoid talking about accessibility relations, I have also assumed that $S$ is consistent relative to S5. It is worth noting that - unless one assumes that the language is countable - the Completeness Theorem assumes a weak version of the Axiom of Choice, so the resulting characterization of admissibility will be nonconstructive.)

${ }^{8}$ On the Principle of Recombination, see Lewis 1986, §1.8. For other approaches to grounding admissibility see Fine 1994, and Peacocke 1999, ch. 4.

${ }^{9}$ For a sparse conception of possible worlds, see Stalnaker's "On What There Isn't (But Might Have Been)" (2012). Stalnaker makes clear that he does not see sparseness as an obstacle for doing Kripke-semantics. 
for example, a possible world $w_{1}$ according to which I have a sister who is a philosopher and might have been a cellist rather than a philosopher, but no possible world according to which it is true of the specific individual who would have been my sister had $w_{1}$ obtained that she exists. (Not even $w_{1}$ is such a world, for even though $w_{1}$ is a world according to which I have a sister, it is not a world according to which it is true of some specific individual that she is my sister.) On an abundant conception of possible worlds, on the other hand, there are possible worlds according to which it is true of specific non-existent objects that they exist. There is, for instance, a possible world $w_{2}$ according to which it is true of the very individual who would have been my sister had $w_{1}$ been actualized that she is a cellist rather than a philosopher.

On the sparse conception of possible worlds, the existence of a world is conditional on the existence of the objects the world represents as existing, in the same sort of way that the existence of a set is conditional on the existence of its members. Had $w_{1}$ been actualized, I would have had a sister, and all manner of sets containing that very individual would have existed. But as things stand, my sister doesn't exist, and neither do sets having her as a member. Similarly - the story would go- had $w_{1}$ been actualized, I would have had a sister, and a world according to which that very individual is a cellist would have existed. But as things stand, my sister doesn't exist, and neither do possible worlds according to which she herself exists.

The absence of $w_{2}$ does not prevent a defender of the sparse conception from using possible worlds to determine a truth-value for SISTER. For, on the assumption that possible worlds track metaphysical possibility, the existence of $w_{1}$ is enough to guarantee that SISTER is true. But the absence of $w_{2}$ does mean that the sparse worlds do not by themselves deliver the ontology that would be needed to give a Kripke-semantics for a sentence like SISTER. For, as emphasized above, a Kripke-semantics will only count SISTER as true if the range of one's metalinguistic quantifiers contains both $w_{1}$ and $w_{2}$.

Fortunately, a sparse ontology of possible worlds is enough to guarantee the existence of a notion of admissibility relative to which an $a$-worlds semantics assigns the right truth-value to every sentence in the language (see footnote 7). So it is open to the sparse theorist to use admissible $a$-worlds, rather than possible worlds, for the purposes of semantic theorizing. The upshot is not, of course, that one has done away with one's specialized modal ontology, since possible 
worlds may be needed for the project of pinning down the crucial notion of admissibility (or for the project of explaining what modal truth consists in). But by using $a$-worlds as the basis of one's semantics, the requirements on one's modal ontology are confined to needs of these non-semantic projects.

A related point can be made with respect to mere possibilia. The availability of $a$-worlds means that there is no need to postulate mere possibilia (or specialized surrogates, such as Plantinga's individual essences) as far as the project of developing a Kripke-semantics for modal languages is concerned. ${ }^{10}$

\section{Interlude: The Principle of Representation}

In previous sections I have made informal remarks about the ways in which $a$-worlds represent possibilities. The purpose of this interlude is to be more precise. (Uninterested readers may skip ahead to section 6.)

When $\langle D, I\rangle$ is considered in isolation from other $a$-worlds, anything that can be said about the possibility represented by $\langle D, I\rangle$ is a consequence of the following principle:

\section{REPRESENTATION PRINCIPLE (Isolated-World Version)}

According to the possibility represented by $\langle D, I\rangle, p$ if and only if

there is a sentence $s$ of $L$ such that $s$ says that $p$ and $s$ is true at $\langle D, I\rangle$.

Accordingly, when considered in isolation from other $a$-worlds, $\left\langle D_{2}, I_{2}\right\rangle$ and $\left\langle D_{3}, I_{3}\right\rangle$ represent the same possibility. It is the possibility that there be exactly one thing and that it be a cellist but not a philosopher.

We shall normally assume that $L$ (and therefore $L^{\diamond}$ ) contains a name for every object in the domain of $L$. With this assumption in place, the following is a consequence of the Representation Principle:

Suppose $z$ is in the domain of $L$. Then $z$ exists according to the possibility represented by $\langle D, I\rangle$ just in case $\langle z$, "actual" $\rangle$ is in $D$.

${ }^{10}$ See Plantinga 1976. For a critique of Plantinga, see Fine 1985. 
In particular, one gets the result that none of the objects in the domain of $L$ exists according to the possibility represented by $\left\langle D_{2}, I_{2}\right\rangle$ (since $\ulcorner\exists x(x=\mathrm{C})\urcorner$ is false at $\left\langle D_{2}, I_{2}\right\rangle$ for any constant $\mathrm{C}$ in $L$ ), and that I exist according to the possibility represented by $\left\langle D_{1}, I_{1}\right\rangle$ (since " $\exists x(x=\mathrm{AR})$ " is true at $\left.\left\langle D_{1}, I_{1}\right\rangle\right)$.

So much for considering $a$-worlds in isolation. When they are considered in the context of a space of $a$-worlds, linking plays a role. So there is slightly more to be said about the possibilities that they represent. Let $A$ be a space of $a$-worlds and let $\langle D, I\rangle$ be in $A$. Then anything that can be said about the possibility represented by $\langle D, I\rangle$ in the context of $A$ is a consequence of the following principle:

\section{Representation Principle (Official Version)}

1. According to the possibility represented by $\langle D, I\rangle$ in the context of $A, p$

if and only if

there is a sentence $s$ of $L^{\diamond}$, such that $s$ says that $p$ and $s$ is true at $\langle D, I\rangle$ in the Kripke-model based on $A$.

2. Let $\left\langle D^{*}, I^{*}\right\rangle$ be an arbitrary $a$-world in $A$. Let $\left\ulcorner\exists x_{1} \ldots x_{k}\right.$ $\left.\phi\left(x_{1} \ldots x_{k}\right)\right\urcorner$ and $\left\ulcorner\exists x_{1} \ldots x_{k} \gamma\left(x_{1} \ldots x_{k}\right)\right\urcorner$ be sentences of $L^{\diamond}$ which say, respectively, that $x_{1} \ldots x_{k}$ are $F$ and that $x_{1} \ldots x_{k}$ are $G$. Assume that $\left\ulcorner\exists x_{1} \ldots x_{k} \phi\left(x_{1} \ldots x_{k}\right)\right\urcorner$ is true at $\langle D, I\rangle$ in $A$ and that $\left\ulcorner\exists x_{1} \ldots x_{k} \gamma\left(x_{1} \ldots x_{k}\right)\right\urcorner$ is true at $\left\langle D^{*}, I^{*}\right\rangle$ in $A$. Then:

as one is inclined to put it, some of the individuals that are $\mathrm{F}$ according to the possibility represented by $\langle D, I\rangle$ in the context of $A$ are the very same individuals as some of the individuals that are $\mathrm{G}$ according to the possibility represented by $\left\langle D^{*}, I^{*}\right\rangle$ in the context of $A$

if and only if

one of the sequences of pairs that witnesses $\left\ulcorner\exists x_{1} \ldots x_{k}\right.$ $\left.\phi\left(x_{1} \ldots x_{k}\right)\right\urcorner$ at $\langle D, I\rangle$ in $A$ is identical to one of the sequences of pairs that witnesses $\left\ulcorner\exists x_{1} \ldots x_{k} \gamma\left(x_{1} \ldots x_{k}\right)\right\urcorner$ at $\left\langle D^{*}, I^{*}\right\rangle$ in the Kripke-model based on $A$. 
When $A$ includes both $\left\langle D_{1}, I_{1}\right\rangle$ and $\left\langle D_{2}, I_{2}\right\rangle$, the first clause yields the result that, according to the possibility represented by $\left\langle D_{2}, I_{2}\right\rangle$ in the context of $A$, there is a cellist who might have been my sister. And the two clauses together yield the slightly stronger result that - as one is inclined to put it - the individual who is a cellist according to the possibility represented by $\left\langle D_{2}, I_{2}\right\rangle$ in the context of $A$ is the very same object as the individual who is my sister according to the possibility represented by $\left\langle D_{1}, I_{1}\right\rangle$ in the context of $A$.

A consequence of the Principle of Representation is that the possibilities represented by $a$-worlds are not maximally specific. Suppose, for example, that the property of tallness is not expressible in $L$. Then the possibility represented by $\left\langle D_{1}, I_{1}\right\rangle$ is compatible with a more specific possibility whereby my sister is tall and is also compatible with a more specific possibility whereby my sister is not tall. On the other hand, the possibilities represented by $a$-worlds are maximally specific as far as the language is concerned: one can only add specificity to the possibility represented by an $a$-world by employing distinctions that cannot be expressed in $L^{\diamond}$.

The Principle of Representation can be used to determine which properties of an $a$-world are essential to its representing the possibility that it represents, and which ones are merely artifactual. It entails, for example, that $\left\langle D_{2}, I_{2}\right\rangle$ and $\left\langle D_{3}, I_{3}\right\rangle$ represent the same possibility when considered in isolation, so any differences between them are merely artifactual. In particular, the use of $\langle$ Socrates, "nonactual" $\rangle$ in $\left\langle D_{2}, I_{2}\right\rangle$ is merely artifactual. On the other hand, $\left\langle D_{2}, I_{2}\right\rangle$ and $\left\langle D_{3}, I_{3}\right\rangle$ represent different possibilities when considered in the context of $\left\{\left\langle D_{1}, I_{1}\right\rangle,\left\langle D_{2}, I_{2}\right\rangle,\left\langle D_{3}, I_{3}\right\rangle\right\}$. For whereas according to $\left\langle D_{2}, I_{2}\right\rangle$ there is a cellist who might have been my sister, according to $\left\langle D_{3}, I_{3}\right\rangle$ there is a cellist who couldn't have been my sister. So the use of $\langle$ Socrates, "nonactual" $\rangle$ in $\left\langle D_{2}, I_{2}\right\rangle$ is essential in the context of $\left\{\left\langle D_{1}, I_{1}\right\rangle,\left\langle D_{2}, I_{2}\right\rangle,\left\langle D_{3}, I_{3}\right\rangle\right\}$. This is not to say, however, that a possibility whereby there is a cellist who might have been my sister can only be represented by an $a$-world if the $a$-world contains $\langle$ Socrates, "nonactual" $\rangle$. For the possibilities represented by $\left\langle D_{1}, I_{1}\right\rangle$, $\left\langle D_{2}, I_{2}\right\rangle$, and $\left\langle D_{3}, I_{3}\right\rangle$ in the context of $\left\{\left\langle D_{1}, I_{1}\right\rangle,\left\langle D_{2}, I_{2}\right\rangle,\left\langle D_{3}, I_{3}\right\rangle\right\}$ are precisely the possibilities represented by $\left\langle D_{4}, I_{4}\right\rangle,\left\langle D_{3}, I_{3}\right\rangle$, and $\left\langle D_{2}, I_{2}\right\rangle$, respectively, in the context of $\left\{\left\langle D_{4}, I_{4}\right\rangle,\left\langle D_{3}, I_{3}\right\rangle,\left\langle D_{2}, I_{2}\right\rangle\right\}$.

When I speak of the possibility that an $a$-world represents what I will usually have in mind is the possibility that is represented in the context of the space of all admissible $a$-worlds. 


\section{The Dot-Notation}

I would like to introduce a further piece of notation: the dot. The dot is a bit like a function that takes representations to the objects represented. Suppose I am seeing a play according to which I have a sister; applying the dot-function is like shifting my attention from the actor who is representing my sister to the character represented (i.e. my sister).

Consider the following two formulas:

$$
[\mathrm{F}(x)]_{w} \quad[\mathrm{~F}(\dot{x})]_{w}
$$

For $w$ a fixed representation, the undotted formula is satisfied by all and only objects $z$ such that $w$ represents a possibility whereby $z$ is an $F$; the dotted formula, on the other hand, is satisfied by all and only objects $z$ such that $z$ is used by $w$ to represent something as being an $F$. Thus, if $p$ is a performance of a play according to which I have a sister, the actor playing my sister satisfies " $[\operatorname{Sister}(\mathrm{AR}, \dot{x})]_{p}$ " but not "[Sister $(\mathrm{AR}, x)]_{p}$ " (since the performance uses the actor to represent someone as being my sister, but the performance does not represent a scenario whereby I have that actor as my sister). And I satisfy " $[\exists y \operatorname{Sister}(x, y)]_{p}$ " but not " $[\exists y \operatorname{Sister}(\dot{x}, y)]_{p}$ " (since the performance represents a scenario whereby I have a sister, but - unlike the actors and props - I am not used by the performance to represent anything).

Now consider how the dot-notation might be cashed out from the perspective of a Lewisian. Let $l_{1}$ be a Lewisian world representing a possibility whereby $I$ have a sister. Accordingly, $l_{1}$ contains an individual $a_{1}$, who is my counterpart, and an individual $s_{1}$, who is $a_{1}$ 's sister. Now consider the following two formulas:

$$
[\operatorname{Sister}(\mathrm{AR}, x)]_{l_{1}} \quad[\operatorname{Sister}(\mathrm{AR}, \dot{x})]_{l_{1}}
$$

From the perspective of the Lewisian, no inhabitant of the actual world satisfies the undotted formula. For no inhabitant of the actual world could have been my sister; so - on the assumption that Lewisian worlds track metaphysical possibility - no inhabitant of the actual world is such that $l_{1}$ represents a possibility whereby she is my sister. The dotted formula, on the other hand, is satisfied by $s_{1}$, since she is used by $l_{1}$ to represent something as being my sister.

Here is a second pair of examples:

$$
[\exists y \operatorname{Sister}(x, y)]_{l_{1}} \quad[\exists y \operatorname{Sister}(\dot{x}, y)]_{l_{1}}
$$


The undotted formula is satisfied by me, since $l_{1}$ represents a possibility whereby I have a sister. But it is not satisfied by $a_{1}$. For although it is true that $a_{1}$ has a sister in $l_{1}, l_{1}$ represents a possibility whereby $I$ have a sister, not a possibility whereby my counterpart has a sister. The dotted formula, on the other hand, is satisfied by $a_{1}$, since $a_{1}$ is used by $l_{1}$ to represent something as having a sister (i.e. me). But the dotted formula is not satisfied by me, since it is only the inhabitants of $l_{1}$ that do any representing for $l_{1}$, and I am an inhabitant of the actual world.

Let me now illustrate how the dot-notation works from the perspective of the modal actualist, with $a$-worlds in place of Lewisian worlds. (A detailed semantics is given in Appendix A.) Here is the first pair of examples (where $w_{1}$ is the $a$-world $\left\langle D_{1}, I_{1}\right\rangle$ from section 3):

$$
[\operatorname{Sister}(\mathrm{AR}, x)]_{w_{1}}
$$$$
[\operatorname{Sister}(\mathrm{AR}, \dot{x})]_{w_{1}}
$$

Since $I_{1}$ ("Sister") $=\{\langle\langle$ Agustín, "actual" $\rangle$, $\langle$ Socrates, "nonactual" $\rangle\rangle\}$, $w_{1}$ represents a possibility whereby I have a sister who doesn't actually exist. Accordingly, from the perspective of a modal actualist, there is no $z$ such that $w_{1}$ represents the possibility that $z$ is my sister. So, from the perspective of the modal actualist, nothing satisfies the undotted formula. The dotted formula, on the other hand, is satisfied

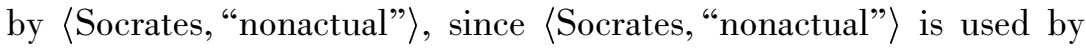
$w_{1}$ to represent something as being my sister.

Now consider the second pair of examples:

$$
[\exists y \operatorname{Sister}(x, y)]_{w_{1}} \quad[\exists y \operatorname{Sister}(\dot{x}, y)]_{w_{1}}
$$

Since the pair $\langle\langle$ Agustín, "actual" $\rangle$, $\langle$ Socrates, "nonactual" $\rangle\rangle$ is in $I_{1}$ ("Sister"), $w_{1}$ represents a possibility whereby I have a sister. The undotted formula is therefore satisfied by me. But it is not satisfied by 〈Agustín, "actual"〉 because $w_{1}$ does not represent a possibility whereby any ordered-pairs have sisters. The dotted formula, on the other hand, is satisfied by 〈Agustín, "actual" $\rangle$, since 〈Agustín, "actual"〉 is used by $w_{1}$ to represent something as having a sister (i.e. me). But it is not satisfied by me, since it is only orderedpairs that do any representing in $w_{1}$, and I am not an ordered-pair.

\section{Inference in a Language with the Dot-Notation}

The semantics for $a$-worlds that is supplied in Appendix A guarantees the truth of every instance of the following schemas: 
1. Validity

$[\psi]_{w}$ (where $\psi$ is valid in a negative free logic)

2. Conjunction

$[\psi \wedge \theta]_{w} \leftrightarrow\left([\psi]_{w} \wedge[\theta]_{w}\right)$

3. Negation

$[\neg \psi]_{w} \leftrightarrow \neg[\psi]_{w}$

4. Quantification

$[\exists y(\phi(y))]_{w} \leftrightarrow \exists y\left([\dot{y}=\dot{y}]_{w} \wedge[\phi(\dot{y})]_{w}\right)$ (where $y$ is a non-worldvariable $)^{11}$

$\left[\exists w^{\prime}(\phi)\right]_{w} \leftrightarrow \exists w^{\prime}\left([\phi]_{w}\right)$ (where $w^{\prime}$ is a world-variable)

5. Trivial accessibility ${ }^{12}$

$\left[[\phi]_{w}\right]_{w^{\prime}} \leftrightarrow[\phi]_{w}$

6. Identity

$[v=v]_{w} \leftrightarrow[\exists y(y=v)]_{w}$

$x=y \rightarrow\left([\phi(\dot{x})]_{w} \rightarrow[\phi(\dot{y})]_{w}\right)$

$[\dot{x}=\dot{y}]_{w} \rightarrow\left([\dot{x}=\dot{x}]_{w} \wedge x=y\right)$

(where $v$ may occur dotted or undotted)

7. Atomic Predication

$\left[\mathrm{F}_{j}^{n}\left(v_{1}, \ldots, v_{n}\right)\right]_{w} \rightarrow\left(\left[v_{1}=v_{1}\right]_{w} \wedge \ldots \wedge\left[v_{n}=v_{n}\right]_{w}\right)$

(where the $v_{i}$ may occur dotted or undotted)

8. Names

$[\psi(c)]_{w} \leftrightarrow \exists x\left(x=c \wedge[\psi(x)]_{w}\right)$ (for $c$ a non-empty name)

Schemas 2-5 are enough to guarantee that any sentence in the actualist's language is equivalent to a sentence in which only atomic formulas occur within the scope of "[ $[. .]_{w}$ ". For instance, the actualist rendering of " $\diamond(\exists x(\operatorname{Phil}(x) \wedge \diamond(\neg \operatorname{Phil}(x))))$ ":

${ }^{11}$ Keep in mind that self-identity may be used as an existence predicate.

${ }^{12}$ If the accessibility relation is non-trivial, what one gets is the following instead:

$$
\left[[\phi]_{w}\right]_{w^{\prime}} \leftrightarrow\left([\phi]_{w} \wedge \operatorname{Accessible}\left(w^{\prime}, w\right)\right) .
$$




$$
\exists w\left[\exists x\left(\operatorname{Phil}(x) \wedge \exists w^{\prime}\left([\neg \operatorname{Phil}(x)]_{w^{\prime}}\right)\right)\right]_{w}
$$

is equivalent to

$$
\exists w \exists x\left([\operatorname{Phil}(\dot{x})]_{w} \wedge \exists w^{\prime}\left(\neg[\operatorname{Phil}(\dot{x})]_{w^{\prime}}\right)\right) .
$$

As a result, the dot-notation allows a language containing the modal operator "[... $]_{w}$ " to have the inferential behavior of a (non-modal) first-order language.

\section{The Expressive Power of the Dot-Notation}

In this section we shall see that a suitably qualified version of the following claim is true: anything the Lewisian can say, the modal actualist can say too - by using the dot-notation.

Here is an example. The Lewisian can use her mighty expressive resources to capture a version of the following thought:

\section{LINKING}

There are possible worlds $w_{1}$ and $w_{2}$ with the following properties: according to $w_{1}$, there is an individual who is a philosopher; according to $w_{2}$, that very individual is a cellist.

It is done as follows:

$$
\exists w_{1} \exists w_{2} \exists x_{1} \exists x_{2}\left(\mathrm{I}\left(x_{1}, w_{1}\right) \wedge \mathrm{I}\left(x_{2}, w_{2}\right) \wedge \operatorname{Phil}\left(x_{1}\right) \wedge \operatorname{Cellist}\left(x_{2}\right) \wedge \mathrm{C}\left(x_{1}, x_{2}\right)\right)
$$

(Read: There are Lewisian worlds $w_{1}$ and $w_{2}$ and individuals $x_{1}$ and $x_{2}$ such that: $(a) x_{1}$ is an inhabitant of $w_{1}$ and $x_{2}$ is an inhabitant of $w_{2},(b) x_{1}$ is a philosopher and $x_{2}$ is a cellist, and $(c) x_{1}$ and $x_{2}$ are counterparts.)

How might this be emulated by a modal actualist equipped with the dot-notation? Consider what happens when one treats the variables in the Lewisian rendering of LINKING as ranging over (admissible) $a$-worlds rather than Lewisian worlds, and carries out the following replacements:

$$
\begin{aligned}
& \mathrm{I}\left(x_{n}, w_{n}\right) \longrightarrow\left[\dot{x}_{n}=\dot{x}_{n}\right]_{w_{n}} \\
& \operatorname{Phil}\left(x_{n}\right) \longrightarrow\left[\operatorname{Phil}\left(\dot{x}_{n}\right)\right]_{w_{n}} \\
& \operatorname{Cellist}\left(x_{n}\right) \longrightarrow\left[\operatorname{Cellist}\left(\dot{x}_{n}\right)\right]_{w_{n}} \\
& \mathrm{C}\left(x_{n}, x_{m}\right) \longrightarrow x_{n}=x_{m}
\end{aligned}
$$


The result is this:

$$
\exists w_{1} \exists w_{2} \exists x_{1} \exists x_{2}\left(\left[\dot{x}_{1}=\dot{x}_{1}\right]_{w_{1}} \wedge\left[\dot{x}_{2}=\dot{x}_{2}\right]_{w_{2}} \wedge\left[\operatorname{Phil}\left(\dot{x}_{1}\right)\right]_{w_{1}} \wedge\left[\operatorname{Cellist}\left(\dot{x}_{2}\right)\right]_{w_{2}} \wedge x_{1}=x_{2}\right)
$$

(Read: There are admissible $a$-worlds $w_{1}$ and $w_{2}$ and objects $x_{1}$ and $x_{2}$ such that: $(a) x_{1}$ is used by $w_{1}$ to represent something and $x_{2}$ is used by $w_{2}$ to represent something, $(b) x_{1}$ is used by $w_{1}$ to represent a philosopher and $x_{2}$ is used by $w_{2}$ to represent a cellist, and $(c) x_{1}=$ $x_{2}$.)

or equivalently:

$$
\exists w_{1} \exists w_{2} \exists x\left([\operatorname{Phil}(\dot{x})]_{w_{1}} \wedge[\operatorname{Cellist}(\dot{x})]_{w_{2}}\right)
$$

(Read: There are admissible $a$-worlds $w_{1}$ and $w_{2}$ and an object $x$ such that: $x$ is used by $w_{1}$ to represent a philosopher and $x$ is used by $w_{2}$ to represent a cellist.)

What gives the actualist's method its punch is the fact that it generalizes: one can show that there is a systematic transformation of arbitrary Lewisian sentences into dotted actualist sentences which preserves truth-values and inferential conections. ${ }^{13}$ (See Appendix B for details.)

The actualist's transformation-method does not preserve meaning - where Lewisian sentences quantify over Lewisian possibilia, their actualist transformations quantify over $a$-worlds and ordered-pairs.

${ }^{13}$ When I say that the transformation preserves truth-value what I mean is that there is a notion of $a$-world admissibility which guarantees that the actualist transformation of an arbitrary Lewisian sentence is true just in case the original Lewisian sentence would count as true from the perspective of the Lewisian. When I say that the transformation preserves inferential role, what I mean is that a Lewisian sentence $\phi$ follows from a set of Lewisian sentences $\Gamma$ just in case $\phi$ 's transformation follows from the transformations of sentences in $\Gamma$.

The result assumes that atomic predicates in the Lewisian's language other than "I", "C" and "=" (and any set-theoretic vocabulary) be projectable. For a monadic predicate $\mathrm{P}$ to be projectable is for it to be the case that a Lewisian world represents a possibility whereby something is $P$ by containing an inhabitant who is $P$. (And similarly for many-place predicates.) Thus, "Philosopher" is projectable because a Lewisian world represents a possibility whereby something is a philosopher by containing an inhabitant who is a philosopher; but "inhabits a Lewisian world which is part of a pluriverse containing many Lewisian worlds" is not projectable because a Lewisian world does not represent a possibility whereby something inhabits a Lewisian world which is part of a pluriverse containing many Lewisian worlds by containing an inhabitant who inhabits a Lewisian world which is part of a pluriverse containing many Lewisian worlds. 
But meaning-preservation is not what the actualist wants, since she doesn't want to countenance Lewisian possibilia. What she wants is a way of enjoying the theoretical benefits of quantification over Lewisian possibilia within the sober confines of an actualist framework. Here are two examples of ways in which she is able to do so:

\section{Firstorderizing Modal Sentences}

By quantifying over Lewisian possibilia, the Lewisian is able to render any sentence in the language of first-order modal logic in (non-modal) first-order terms. The sentence

$$
\diamond(\exists x(\operatorname{Phil}(x) \wedge \diamond(\operatorname{Cellist}(x))))
$$

(read: there might have been a philosopher who might have been a cellist),

for example, gets rendered as the (non-modal) first-order sentence:

$\exists w_{1} \exists w_{2} \exists x_{1} \exists x_{2}\left(\mathrm{I}\left(x_{1}, w_{1}\right) \wedge \mathrm{I}\left(x_{2}, w_{2}\right) \wedge \operatorname{Phil}\left(x_{1}\right) \wedge \operatorname{Cellist}\left(x_{2}\right) \wedge \mathrm{C}\left(x_{1}, x_{2}\right)\right)$

And Lewis 1968 shows that it can be done in general. ${ }^{14}$

The (non-modal) firstorderizability of modal sentences brings two immediate advantages. The first is that it allows one to think of the inferential connections amongst modal sentences in terms of the inferential connections amongst the corresponding non-modal sentences; the second is that it allows one to read off a semantics for modal sentences from the semantics of the corresponding non-modal sentences.

The actualist transformation-method allows actualists equipped with the dot-notation to enjoy both of these advantages.

\section{Characterizing Intensions}

On a standard way of doing intensional semantics for natural languages, characterizing the semantic value of an expression

${ }^{14}$ As Lewis observes, a feature of the 1968 translation is that " $\forall x \square(\exists y(x=y))$ " turns out to be true. For this reason, I prefer a modification of the translation whereby $(\square \phi)^{\beta}$ is $\forall \beta_{1}\left(W\left(\beta_{1}\right) \rightarrow(\phi)^{\beta_{1}}\right),(\diamond \phi)^{\beta}$ is $\exists \beta_{1}\left(W\left(\beta_{1}\right) \wedge(\phi)^{\beta_{1}}\right)$ and $\left(P\left(x_{1}, \ldots, x_{n}\right)\right)^{\beta}$ is $\exists \gamma_{1} \ldots \exists \gamma_{n}\left(I\left(\gamma_{1}, \beta\right) \wedge C\left(\gamma_{1}, x_{1}\right) \wedge \ldots I\left(\gamma_{n}, \beta\right) \wedge C\left(\gamma_{n}, x_{n}\right) \wedge\right.$ $P\left(\gamma_{1} \ldots, \gamma_{n}\right)$ (for $P$ atomic). The modified translation delivers the same truth-values as a version of Kripke-semantics in which atomic formulas (including identitystatements) can only be satisfied at a world by objects that exist at that world. 
calls for quantification over possibilia. ${ }^{15}$ Oversimplifying a bit, the semantic value of, e.g. "philosopher" might be taken to be the set of pairs $\langle w, z\rangle$ where $w$ is a possible world and $z$ is an (actual or merely possible) individual who is a philosopher at $w$. As emphasized in Lewis 1970, the Lewisian is able to do the job by quantifying over Lewisian possibilia:

$$
[[\text { "philosopher"] }]=\{\langle w, z\rangle: \mathrm{I}(z, w) \wedge \operatorname{Phil}(z)\}
$$

But the actualist transformation-method allows actualists armed with the dot-notation to follow suit, by quantifying over $a$ worlds and ordered pairs:

$$
\left[[\text { "philosopher"] }]=\left\{\langle w, z\rangle:[\dot{z}=\dot{z}]_{w} \wedge[\operatorname{Phil}(\dot{z})]_{w}\right\}\right.
$$

or, equivalently,

$$
\left[[\text { “philosopher"] }]=\left\{\langle w, z\rangle:[\operatorname{Phil}(\dot{z})]_{w}\right\} .\right.
$$

Since the actualist transformation-method preserves inferential connections, the actualist semantics is guaranteed to deliver the same theorems as its Lewisian counterpart. And since the transformation-method preserves truth-value the actualist's axioms will be true just in case their Lewisian counterparts would count as true from the perspective of the Lewisian.

In particular, one can expect the actualist semantics to deliver every instance of the (world-relative) T-schema. For instance:

$$
\operatorname{True}(“ \exists x \operatorname{Phil}(x) ", w) \leftrightarrow\left([\exists x \operatorname{Phil}(x)]_{w}\right)
$$

or, equivalently,

$$
\operatorname{True}(" \exists x \operatorname{Phil}(x) ", w) \leftrightarrow \exists x\left([\operatorname{Phil}(\dot{x})]_{w}\right)
$$

(Read: The object-language sentence " $\exists x \operatorname{Phil}(x)$ " is true at admissible $a$-world $w$ just in case there is an individual which is used by $w$ to represent a philosopher.)

${ }^{15}$ For a representative textbook, see Heim and Kratzer 1998, ch. 12. 


\section{Limitations of the Proposal}

$A$-worlds are subject to an important limitation. ${ }^{16}$ Whereas differences between $a$-worlds are no more fine-grained than is required to make distinctions expressible in one's language, there might be differences amongst Lewisian worlds too fine-grained to be expressed in one's language. ${ }^{17}$

Because of this limitation, some of the metaphysical work that the Lewisian gets out of Lewisian possibilia cannot be replicated by an actualist equipped with the dot-notion. Here is an example. Lewis 1986 treats properties as sets of worldbound individuals. Up to a certain point, the actualist is able to follow suit. When the Lewisian claims that the property of being a philosopher is to be identified with the set of philosophers inhabiting actual or non-actual Lewisian worlds, for instance, the actualist could claim that the set $\left\{\langle z, w\rangle:[\operatorname{Phil}(\dot{z})]_{w}\right\}$ is to be used as a surrogate for the property of being a philosopher. But the strategy breaks down when it comes to properties making finer distinctions than can be expressed in one's language. ${ }^{18}$

In general, whether or not the actualist's limitation turns out to get in the way will depend on whether the job at hand calls for using possibilia to make finer distinctions than can be expressed in one's language. When the job at hand is a piece of semantic theorizing the extra resources are unnecessary: since a semantic theory is ultimately an effort to explain how language is used, it need not be concerned with distinctions too fine-grained to figure in our explanations. But

${ }^{16}$ For discussion of related issues, see Lewis 1986, §3.1. It is worth noting that Lewis's critique is not meant to apply to the sort of project that is the focus of the present essay. Here is Lewis: "When I complain, as I shall, that there are various ways for different possibilities to get conflated in their linguistic descriptions, that may be harmless when we want to use ersatz possibilia to characterize the content of thought for a subject who has no way to distinguish the conflated possibilities in his perception and conduct." (p. 144, footnote).

${ }^{17}$ More precisely, there might be different Lewisian worlds such that every inhabitant of the one world is a counterpart of an inhabitant of the other, and every predicate in the language which is projectable in the sense of footnote 13 is satisfied by inhabitants of one world just in case it is satisfied by the counterparts of those individuals at the other. The distinct possibilities represented by such Lewisian worlds would both be compatible with the less-specific possibility represented by an $a$-world in which the behavior of the predicates mirrors the behavior of the predicates at the Lewisian worlds.

${ }^{18}$ Any set of worldbound individuals containing an inhabitant of one of the Lewisian worlds described in footnote 17 but not its counterpart at the other corresponds to a Lewisian property with no actualist surrogate. 
when the job at hand is metaphysical reduction, matters are otherwise. ${ }^{19}$

\section{APPENDICES}

\section{A. $A$ Semantics ${ }^{20}$}

I give a formal semantics for a language $\mathcal{L}^{w}$ which allows for empty names and contains both the intensional operator $[\ldots]_{w}$ (read "according to $w, \ldots ")$ and the dot-notation. $\mathcal{L}^{w}$ consists of the following symbols:

1. for $n>0$, the $n$-place (non-modal) predicate letters: $\left\ulcorner\mathrm{F}_{1}^{n}\right\urcorner,\left\ulcorner\mathrm{F}_{2}^{n}\right\urcorner$, ... (each with an intended interpretation);

2. for $n>0$, the one-place modal predicate letter $\left\ulcorner\mathrm{B}_{n}\right\urcorner$ (each with an intended interpretation);

3. the identity symbol "=";

4. for $n>0$, the individual non-empty constant-letter $\left\ulcorner c_{n}\right\urcorner$ (each with an intended referent);

5. for $n>0$, the individual empty constant-letter $\left\ulcorner e_{n}\right\urcorner$;

6. the individual constant " $\alpha$ ";

7. the dot "*";

8. the monadic sentential operator "[...]";

9. the monadic sentential operator " $\neg "$ ";

10. the dyadic sentential operator " $\wedge$ ";

11. the quantifier-symbol " $\exists$ ";

${ }^{19}$ For their many helpful comments, I am grateful to Elizabeth Barnes, Ross Cameron, Michael Glanzberg, Ephraim Glick, Caspar Hare, Sally Haslanger, Allen Hazen, Michael Rescorla, Graham Priest, Peter Simons, Bob Stalnaker, Robbie Williams, Steve Yablo, audiences at the University of Leeds, the University of Melbourne and MIT's Work in Progress Seminar. I am especially grateful to two helpful referees for Crítica.

${ }^{20}$ An earlier version of the material in Appendix A appeared as an appendix to my "On Specifying Truth-Conditions", The Philosophical Review, vol. 117, no. 3, 2008, pp. 385-443, and is reprinted here by permission of Duke University Press. 
12. the modal variables: " $w ", " v "$, " $u$ " with or without numerical subscripts;

13. the non-modal variables: " $x$ ", “ $y$ ", " $z$ " with or without numerical subscripts;

14. the auxiliaries "(" and ")".

Undotted terms and formulas are defined as follows:

1. any modal variable is an undotted modal term;

2. " $\alpha$ " is an undotted modal term;

3. any non-modal variable or individual constant-letter is an undotted non-modal term;

4. if $\tau_{1}, \ldots, \tau_{n}$ are undotted non-modal terms, then $\left\ulcorner\mathrm{F}_{i}^{n}\left(\tau_{1}, \ldots\right.\right.$, $\left.\left.\tau_{n}\right)\right\urcorner$ is an undotted formula;

5. if $\tau_{1}$ and $\tau_{2}$ are either both undotted non-modal terms or both undotted modal terms, then $\left\ulcorner\tau_{1}=\tau_{2}\right\urcorner$ is an undotted formula;

6. if $w$ is an undotted modal term, then $\left\ulcorner\mathrm{B}_{i}(w)\right\urcorner$ is an undotted formula;

7. if $\phi$ is an undotted formula and $w$ is an undotted modal term, then $\left\ulcorner[\phi]_{w}\right\urcorner$ is an undotted formula;

8. if $v$ is an undotted (modal or non-modal) variable and $\phi$ is an undotted formula, then $\ulcorner\exists v(\phi)\urcorner$ is an undotted formula;

9. if $\phi$ and $\psi$ are undotted formulas, then $\ulcorner\neg \phi\urcorner$ and $\ulcorner(\phi \wedge \psi)\urcorner$ are undotted formulas;

10. nothing else is an undotted term or formula.

A non-modal term is either an undotted non-modal term or the result of dotting a non-modal variable; a modal term is an undotted modal term; a formula is the result of dotting any free or externally bounded occurrences of non-modal variables in an undotted formula. $^{21}$

Next, we characterize the notion of an $a$-world and of a variable assignment. An $a$-world is a pair $\langle D, I\rangle$ with the following features:

${ }^{21}$ An occurrence of a non-modal variable in an undotted formula is free iff it is not bound by a quantifier; an occurrence of a non-modal variable in an undotted formula is externally bounded iff it is bound by a quantifier which is not within the scope of "[...]". 
1. $D$ is a set of individuals in the range of the non-modal variables, each of which is either of the form $\langle x$, "actual" $\rangle$ or of the form $\langle x$, "nonactual" $\rangle .{ }^{22}$

2. $I$ is a function assigning a subset of $D$ to each 1-place predicateletter, and a subset of $D^{n}$ to each $n$-place predicate letter (for $n<1)$. In addition, if $e$ is an empty name, $I$ may or may not assign a referent to $e$ (and if a referent is assigned, it may or may not be in $D$ ).

The actualized $a$-world $\left\langle D_{\alpha}, I_{\alpha}\right\rangle$ will be singled out for special attention. $D_{\alpha}$ is the set of pairs $\langle z$, "actual" $\rangle$ for $z$ an individual in the range of the non-modal variables; and $I_{\alpha}\left({ }^{\text {" }} \mathrm{F}_{j}^{n}\right.$ ") $)$ is the set of sequences $\left\langle\left\langle z_{1}\right.\right.$, "actual" $\rangle, \ldots\left\langle z_{n}\right.$, "actual" $\left.\rangle\right\rangle$ such that $z_{1} \ldots z_{n}$ are in the range of the non-modal variables and satisfy $F$.

A variable assignment is a function $\sigma$ with the following features:

1. $\sigma$ assigns an $a$-world to each modal variable.

2. $\sigma$ assigns an individual to each non-modal variable.

This puts us in a position to characterize notions of quasi-denotation and quasi-satisfaction. (With a suitable notion of admissibility on board, one can characterize truth and satisfaction for $\mathcal{L}^{w}$. Satisfaction is the special case of quasi-satisfaction in which attention is restricted to admissible $a$-worlds, and truth is the special case of quasi-truth in which attention is restricted to admissible $a$-worlds.) For $v$ a nonmodal variable, $\sigma$ a variable assignment, $\phi$ a formula and $w$ an $a$ world, we characterize the quasi-denotation function $\delta_{\sigma, w}(v)$ and the quasi-satisfaction predicate $\operatorname{Sat}(\phi, \sigma)$. In addition, we characterize an auxiliary ( $a$-world-relative) quasi-satisfaction predicate $\operatorname{Sat}(\phi, \sigma, w)$. We proceed axiomatically, by way of the following clauses:

- If $v$ is a (modal or non-modal) variable, $\delta_{\sigma, w}(v)$ is $\sigma(v)$;

- if $v$ is a non-modal variable, $w$ is an $a$-world and $\sigma(v)$ is an ordered pair of the form $\langle z$, "actual" $\rangle$, then $\delta_{\sigma, w}(\ulcorner\dot{v}\urcorner)$ is the first member of $\sigma(v)$; otherwise $\delta_{\sigma, w}(\ulcorner\dot{v}\urcorner)$ is undefined;

- if $c$ is a non-empty constant-letter and $w$ is an $a$-world, $\delta_{\sigma, w}(c)$ is the intended referent of $c$;

${ }^{22} \mathrm{I}$ assume that $D$ is a set for the sake of simplicity. The assumption can be avoided by characterizing the notion of an $a$-world in second-order terms. This can be done by employing the technique in Rayo and Uzquiano 1999. 
- if $e$ is an empty constant-letter and $w$ is an $a$-world, $\delta_{\sigma, w}(e)$ is the $w$-referent of $e$ if there is one, and is otherwise undefined;

- $\delta_{\sigma, w}(" \alpha ")$ is $\left\langle D_{\alpha}, I_{\alpha}\right\rangle$;

- if $\tau_{1}$ and $\tau_{2}$ are terms (both of them modal or both of them non-modal) and neither of them is an empty constant-letter, then $\operatorname{Sat}\left(\left\ulcorner\tau_{1}=\tau_{2}\right\urcorner, \sigma\right)$ if and only if $\delta_{\sigma, w}\left(\tau_{1}\right)=\delta_{\sigma, w}\left(\tau_{2}\right)$ for arbitrary $w$;

- if $\tau_{1}$ and $\tau_{2}$ are non-modal terms at least one of which is an empty constant-letter, then not-Sat $\left(\left\ulcorner\tau_{1}=\tau_{2}\right\urcorner, \sigma\right)$;

- if $\tau_{1}, \ldots \tau_{n}$ are non-modal terms none of which is an empty constant-letter, then $\operatorname{Sat}\left(\left\ulcorner\mathrm{F}_{i}^{n}\left(\tau_{1}, \ldots, \tau_{n}\right)\right\urcorner, \sigma\right)$ if and only if $F_{i}^{n}\left(\delta_{\sigma, w}\left(\tau_{1}\right), \ldots, \delta_{\sigma, w}\left(\tau_{n}\right)\right)$, where $w$ is arbitrary and $\left\ulcorner\mathrm{F}_{i}^{n}\right\urcorner$ is intended to express $F_{i}^{n}$-ness;

- if $\tau_{1}, \ldots \tau_{n}$ are non-modal terms at least one of which is an empty constant-letter, then not-Sat $\left(\left\ulcorner\mathrm{F}_{i}^{n}\left(\tau_{1}, \ldots, \tau_{n}\right)\right\urcorner, \sigma\right)$;

- if $v$ is a modal variable, $\operatorname{Sat}\left(\left\ulcorner\mathrm{B}_{i}(v)\right\urcorner, \sigma\right)$ if and only if $B_{i}\left(\delta_{\sigma, w}\right.$ $(v))$ for arbitrary $w$, where $\mathbf{B}_{i}$ is intended to express $B_{i}$-ness;

- if $v$ is a non-modal variable, $\operatorname{Sat}(\ulcorner\exists v(\phi)\urcorner, \sigma)$ if and only if there is an individual $z$ in the range of the non-modal variables such that $\operatorname{Sat}\left(\ulcorner\phi\urcorner, \sigma^{v / z}\right)$, where $\sigma^{v / z}$ is just like $\sigma$ except that it assigns $z$ to $v$;

- if $v$ is a modal variable, $\operatorname{Sat}(\ulcorner\exists v(\phi)\urcorner, \sigma)$ if and only if there is an $a$-world $z$ such that $\operatorname{Sat}\left(\ulcorner\phi\urcorner, \sigma^{v / z}\right)$, where $\sigma^{v / z}$ is just like $\sigma$ except that it assigns $z$ to $v$;

- $\operatorname{Sat}(\ulcorner\neg \phi\urcorner, \sigma)$ if and only if it is not the case that $\operatorname{Sat}(\phi, \sigma)$;

- $\operatorname{Sat}(\ulcorner\phi \wedge \psi\urcorner, \sigma)$ if and only if $\operatorname{Sat}(\phi, \sigma)$ and $\operatorname{Sat}(\psi, \sigma)$;

- $\operatorname{Sat}\left(\left\ulcorner[\phi]_{w}\right\urcorner, \sigma\right)$ if and only if $\operatorname{Sat}\left(\phi, \sigma^{\prime}, \sigma(w)\right)$, where $\sigma^{\prime}(x)=$ $\sigma(x)$ for $x$ a modal variable and $\sigma^{\prime}(x)=\langle\sigma(x)$, "actual" $\rangle$ for $x$ a non-modal variable;

- if $\tau_{1}$ and $\tau_{2}$ are non-modal terms neither of which is an empty constant-letter without a $w$-reference, then $\operatorname{Sat}\left(\left\ulcorner\tau_{1}=\tau_{2}\right\urcorner, \sigma, w\right)$ if and only if $\delta_{\sigma, w}\left(\tau_{1}\right)$ is in the domain of $w$ and is identical to $\delta_{\sigma, w}\left(\tau_{2}\right)$; 
- if $\tau_{1}$ and $\tau_{2}$ are non-modal terms at least one of which is a constant-letter without a $w$-reference, then not-Sat $\left(\left\ulcorner\tau_{1}=\tau_{2}\right\urcorner\right.$, $\sigma, w)$;

- if $\tau_{1}$ and $\tau_{2}$ are modal terms, then $\operatorname{Sat}\left(\left\ulcorner\tau_{1}=\tau_{2}\right\urcorner, \sigma, w\right)$ if and only if $\delta_{\sigma, w}\left(\tau_{1}\right)=\delta_{\sigma, w}\left(\tau_{2}\right)$ for arbitrary $w$;

- if $\tau_{1}, \ldots \tau_{n}$ are non-modal terms none of which is a constantletter without a $w$-reference, then $\operatorname{Sat}\left(\left\ulcorner\mathrm{F}_{i}^{n}\left(\tau_{1}, \ldots, \tau_{n}\right)\right\urcorner, \sigma, w\right)$ if and only if $\left\langle\delta_{\sigma, w}\left(\tau_{1}\right), \ldots, \delta_{\sigma, w}\left(\tau_{n}\right)\right\rangle$ is in the $w$-extension of $\left\ulcorner\mathrm{F}_{i}^{n}\right\urcorner$;

- if $\tau_{1}, \ldots \tau_{n}$ are non-modal terms at least one of which is a constant-letter without a $w$-reference, then $\operatorname{not}-\operatorname{Sat}\left(\left\ulcorner\mathrm{F}_{i}^{n}\left(\tau_{1}, \ldots\right.\right.\right.$, $\left.\left.\left.\tau_{n}\right)\right\urcorner, \sigma, w\right)$;

- if $v$ is a modal term, $\operatorname{Sat}\left(\left\ulcorner\mathrm{B}_{i}(v)\right\urcorner, \sigma, w\right)$ if and only if $B_{i}\left(\delta_{\sigma, w}\right.$ $(v))$, where $\left\ulcorner\mathrm{B}_{i}\right\urcorner$ is intended to express $B_{i}$-ness;

- if $v$ is a non-modal variable, $\operatorname{Sat}(\ulcorner\exists v(\phi)\urcorner, \sigma, w)$ if and only if there is an individual $z$ in the domain of $w$ such that $\operatorname{Sat}\left(\ulcorner\phi\urcorner, \sigma^{v / z}, w\right)$, where $\sigma^{v / z}$ is just like $\sigma$ except that it assigns $z$ to $v$;

- if $v$ is a modal variable, $\operatorname{Sat}(\ulcorner\exists v(\phi)\urcorner, \sigma, w)$ if and only if there is an $a$-world $z$ such that $(a)$ any empty constant-letter which is assigned a referent by $w$ is assigned the same referent by $z$, and (b) $\operatorname{Sat}\left(\ulcorner\phi\urcorner, \sigma^{v / z}, w\right)$, where $\sigma^{v / z}$ is just like $\sigma$ except that it assigns $z$ to $v$;

- $\operatorname{Sat}(\ulcorner\neg \phi\urcorner, \sigma, w)$ if and only if it is not the case that $\operatorname{Sat}(\phi, \sigma$, $w)$

- $\operatorname{Sat}(\ulcorner\phi \wedge \psi\urcorner, \sigma, w)$ if and only if $\operatorname{Sat}(\phi, \sigma, w)$ and $\operatorname{Sat}(\psi, \sigma, w)$;

- $\operatorname{Sat}\left(\left\ulcorner[\phi]_{u}\right\urcorner, \sigma, w\right)$ if and only if $\operatorname{Sat}(\phi, \sigma, \sigma(u))$.

Finally, we say that a formula $\phi$ is quasi-true if and only if $\operatorname{Sat}(\phi, \sigma)$ for any variable assignment $\sigma$.

\section{B. A Transformation}

The purpose of this appendix is to explain how the transformation from Lewisian sentences to dotted actualist sentences works in general. I shall assume that the Lewisian language is a two-sorted firstorder language, with world-variables " $w_{1}$ ", " $w_{2}$ ", etc. ranging over 
Lewisian worlds, and individual-variables " $x_{1}$ ", " $x_{2}$ ", etc. ranging over world-bound individuals in the Lewisian pluriverse. The language contains no function-letters; there is a world-constant " $\alpha$ " referring to the actual Lewisian world and individual-constants " $c_{1}$ ", " $c_{2}$ ", etc. referring to world-bound individuals. The only atomic predicates are "I" (which takes an individual-variable and a worldvariable), "C" (which takes two individual-variables), "=" (which takes $(i)$ two world-variables, (ii) two individual-variables, (iii) a world-constant and a world-variable, or (iv) an individual-constant and an individual-variable) and, for each $j,\left\ulcorner\mathrm{P}_{j}^{n}\right\urcorner$ (which takes $n$ individual-variables). (If one likes, one can also take the language to contain set-theoretic vocabulary.) Finally, I shall assume that universal quantifiers are defined in terms of existential quantifiers in the usual way, and that logical connectives other than " $\wedge$ " and " $\neg$ " are defined in terms of " $\wedge$ " and " $\neg$ " in the usual way.

The plan is to proceed in two steps. The first is to get the Lewisian sentence into a certain kind of normal form; the second is to convert the normal-form sentence into a dotted actualist sentence. Here is a recipe for getting an arbitrary Lewisian sentence into normal form:

1. Start by relabeling variables in such a way that no worldvariable has the same index as an individual-variable;

2. next, replace each occurrence of $\left\ulcorner\mathrm{I}\left(x_{j}, w_{k}\right)\right\urcorner$ by $\left\ulcorner w_{j}=w_{k}\right\urcorner$;

3. then replace each occurrence of the atomic formula $\left\ulcorner\mathrm{P}_{j}^{n}\left(x_{k_{1}}\right.\right.$, $\left.\left.\ldots, x_{k_{n}}\right)\right\urcorner$ by

$$
\left(\mathrm{P}_{j}^{n}\left(x_{k_{1}}, \ldots, x_{k_{n}}\right) \wedge w_{k_{1}}=w_{k_{2}} \wedge \ldots \wedge w_{k_{1}}=w_{k_{n}}\right),
$$

each occurrence of $\left\ulcorner c_{j}=x_{k}\right\urcorner$ by $\left\ulcorner\left(c_{j}=x_{k} \wedge \alpha=w_{k}\right)\right\urcorner$, and each occurrence of $\left\ulcorner x_{j}=x_{k}\right\urcorner$ by $\left\ulcorner\left(x_{j}=x_{k} \wedge w_{j}=w_{k}\right)\right\urcorner{ }^{23}$

4. Finally, replace each occurrence of $\left\ulcorner\exists x_{j}(\ldots)\right\urcorner$ by $\left\ulcorner\exists x_{j} \exists w_{j}\left(\mathrm{I}\left(x_{j}\right.\right.\right.$, $\left.\left.\left.w_{j}\right) \wedge \ldots\right)\right\urcorner$.

On the assumption that $\left\ulcorner\mathrm{P}_{j}^{n}\right\urcorner$ is projectable (and, hence, that $\left\ulcorner\mathrm{P}_{j}^{n}\right.$ $\left.\left(x_{k_{1}}, \ldots, x_{k_{n}}\right)\right\urcorner$ can only be true if $x_{k_{1}}, \ldots, x_{k_{n}}$ are world-mates), it is easy to verify that this procedure respects truth-value. (For a characterization of projectability, see footnote 13.)

Here is an example. The Lewisian sentence

${ }^{23}$ These three replacements are needed to secure the base clause in the induction below. 
$\exists w_{17} \exists x_{2} \exists x_{5}\left(\mathrm{I}\left(x_{2}, w_{17}\right) \wedge \operatorname{Sister}\left(x_{2}, x_{5}\right)\right)$

(Read: There is a Lewisian world $w_{17}$, an individual $x_{2}$, and an individual $x_{5}$ such that $x_{2}$ is an inhabitant of $w_{17}$ and $x_{2}$ has $x_{5}$ as a sister.)

gets rewritten as:

$\exists w_{17} \exists x_{2} \exists w_{2}\left(\mathrm{I}\left(x_{2}, w_{2}\right) \wedge \exists x_{5} \exists w_{5}\left(\mathrm{I}\left(x_{5}, w_{5}\right) \wedge w_{2}=w_{17} \wedge\right.\right.$ $\left.\left.\operatorname{Sister}\left(x_{2}, x_{5}\right) \wedge w_{2}=w_{5}\right)\right)$

(Read: There is a Lewisian world $w_{17}$, an individual $x_{2}$ inhabiting Lewisian world $w_{2}$, and an individual $x_{5}$ inhabiting Lewisian world $w_{5}$ such that $w_{2}$ is identical to $w_{17}$, $x_{2}$ has $x_{5}$ as a sister and $w_{2}$ is identical to $w_{5}$.)

Once one has a Lewisian sentence in normal form, it can be transformed into a dotted actualist sentence by carrying out the following replacements:

$$
\begin{aligned}
\mathrm{I}\left(x_{j}, w_{j}\right) & \longrightarrow\left[\exists y\left(y=\dot{x}_{j}\right)\right]_{w_{j}} \\
\mathrm{P}_{j}^{n}\left(x_{k_{1}}, \ldots, x_{k_{n}}\right) & \longrightarrow\left[\mathrm{P}_{j}^{n}\left(\dot{x}_{k_{1}}, \ldots, \dot{x}_{k_{n}}\right)\right]_{w_{k_{1}}} \\
\mathrm{C}\left(x_{j}, x_{k}\right) & \longrightarrow x_{j}=x_{k} \\
c_{j}=x_{k} & \longrightarrow\left[c_{j}=\dot{x}_{k}\right]_{w_{k}}
\end{aligned}
$$

Here is an example. The Lewisian rendering of " $\vee\left(\exists x_{1} \exists x_{2} \operatorname{Sister}\left(x_{1}\right.\right.$, $\left.\left.x_{2}\right)\right)^{\prime \prime}$ is

$$
\exists w_{3} \exists x_{1} \exists x_{2}\left(\mathrm{I}\left(x_{1}, w_{3}\right) \wedge \mathrm{I}\left(x_{2}, w_{3}\right) \wedge \operatorname{Sister}\left(x_{1}, x_{2}\right)\right)
$$

whose normal form

$$
\begin{aligned}
\exists w_{3} \exists x_{1} \exists w_{1}\left(\mathrm { I } ( x _ { 1 } , w _ { 1 } ) \wedge \exists x _ { 2 } \exists w _ { 2 } \left(\mathrm{I}\left(x_{2}, w_{2}\right)\right.\right. & \wedge w_{1}=w_{3} \wedge w_{1}=w_{3} \wedge \\
& \left.\left.\operatorname{Sister}\left(x_{1}, x_{2}\right) \wedge w_{1}=w_{2}\right)\right)
\end{aligned}
$$

gets transformed by the actualist into

$$
\begin{gathered}
\exists w_{3} \exists x_{1} \exists w_{1}\left([ \exists y ( y = \dot { x } _ { 1 } ) ] _ { w _ { 1 } } \wedge \exists x _ { 2 } \exists w _ { 2 } \left(\left[\exists y\left(y=\dot{x}_{2}\right)\right]_{w_{2}} \wedge w_{1}=\right.\right. \\
\left.\left.w_{3} \wedge w_{1}=w_{3} \wedge\left[\operatorname{Sister}\left(\dot{x}_{1}, \dot{x}_{2}\right)\right]_{w_{1}} \wedge w_{1}=w_{2}\right)\right)
\end{gathered}
$$

which boils down to:

$$
\exists w_{3} \exists x_{1} \exists x_{2}\left(\left[\operatorname{Sister}\left(\dot{x}_{1}, \dot{x}_{2}\right)\right]_{w_{3}}\right)
$$


(Read: There are objects $x_{1}$ and $x_{2}$ and an admissible $a$ world $w$ such that $x_{1}$ and $x_{2}$ are used by $w$ to represent someone's having a sister.)

and is guaranteed by the "Appendix A Semantics" to be equivalent to

$$
\exists w_{3}\left(\left[\exists x_{1} \exists x_{2} \operatorname{Sister}\left(x_{1}, x_{2}\right)\right]_{w_{3}}\right)
$$

(Read: There is an admissible $a$-world $w$ according to which there are individuals $x_{1}$ and $x_{2}$ such that $x_{1}$ has $x_{2}$ as a sister.)

which is the actualist's rendering of " $\diamond\left(\exists x_{1} \exists x_{2} \operatorname{Sister}\left(x_{1}, x_{2}\right)\right)$ ". of

Here is a slightly more complex example. The actualist's rendering

There are possible worlds $w_{1}$ and $w_{2}$ with the following properties: according to $w_{1}$, there is an individual who is my sister and a philosopher; according to $w_{2}$, that very individual is a cellist rather than a philosopher.

is

$$
\begin{aligned}
& \exists w_{4} \exists w_{5} \exists x_{1} \exists x_{2} \exists x_{3}( \\
& \mathrm{I}\left(x_{1}, w_{4}\right) \wedge \mathrm{I}\left(x_{2}, w_{4}\right) \wedge \mathrm{I}\left(x_{3}, w_{5}\right) \wedge \\
& \exists x_{6}\left(\mathrm{AR}=x_{6} \wedge \mathrm{C}\left(x_{6}, x_{1}\right)\right) \wedge \mathrm{C}\left(x_{2}, x_{3}\right) \wedge \\
& \left.\operatorname{Sister}\left(x_{1}, x_{2}\right) \wedge \operatorname{Phil}\left(x_{2}\right) \wedge \operatorname{Cellist}\left(x_{3}\right) \wedge \neg \operatorname{Phil}\left(x_{3}\right)\right)
\end{aligned}
$$

whose normal form

$$
\begin{gathered}
\exists w_{4} \exists w_{5} \exists x_{1} \exists w_{1}\left(\mathrm { I } ( x _ { 1 } , w _ { 1 } ) \wedge \exists x _ { 2 } \exists w _ { 2 } \left(\mathrm { I } ( x _ { 2 } , w _ { 2 } ) \wedge \exists x _ { 3 } \exists w _ { 3 } \left(\mathrm{I}\left(x_{3}, w_{4}\right) \wedge\right.\right.\right. \\
w_{1}=w_{4} \wedge w_{2}=w_{4} \wedge w_{3}=w_{5} \wedge \\
\exists x_{6} \exists w_{6}\left(\mathrm{I}\left(x_{6}, w_{6}\right) \wedge \mathrm{AR}=x_{6} \wedge \alpha=w_{6} \wedge \mathrm{C}\left(x_{6}, x_{1}\right)\right) \wedge \mathrm{C}\left(x_{2}, x_{3}\right) \wedge \\
\left.\left.\left.\quad \operatorname{Sister}\left(x_{1}, x_{2}\right) \wedge \operatorname{Phil}\left(x_{2}\right) \wedge \operatorname{Cellist}\left(x_{3}\right) \wedge \neg \operatorname{Phil}\left(x_{3}\right)\right)\right)\right)
\end{gathered}
$$

gets transformed by the actualist into 


$$
\begin{gathered}
\exists w_{4} \exists w_{5} \exists x_{1} \exists w_{1}\left([ \exists y ( y = \dot { x } _ { 1 } ) ] _ { w _ { 1 } } \wedge \exists x _ { 2 } \exists w _ { 2 } \left(\left[\exists y\left(y=\dot{x}_{2}\right)\right]_{w_{2}} \wedge\right.\right. \\
\exists x_{3} \exists w_{3}\left(\left[\exists y\left(y=\dot{x}_{3}\right)\right]_{w_{3}} \wedge w_{1}=w_{4} \wedge w_{2}=w_{4} \wedge w_{3}=w_{5} \wedge\right. \\
\exists x_{6} \exists w_{6}\left(\left[\exists y\left(y=\dot{x}_{6}\right)\right]_{w_{6}} \wedge\left[\operatorname{AR}=\dot{x}_{6}\right]_{w_{6}} \wedge \alpha=w_{6} \wedge x_{6}=x_{1}\right) \wedge x_{2}=x_{3} \wedge \\
{\left[\operatorname{Sister}\left(\dot{x}_{1}, \dot{x}_{2}\right)\right]_{w_{1}} \wedge w_{1}=w_{2} \wedge\left[\operatorname{Phil}\left(\dot{x}_{2}\right)\right]_{w_{2}} \wedge} \\
\left.\left.\left.\left[\operatorname{Cellist}\left(\dot{x}_{3}\right)\right]_{w_{3}} \wedge \neg\left[\operatorname{Phil}\left(\dot{x}_{3}\right)\right]_{w_{3}}\right)\right)\right)
\end{gathered}
$$

which boils down to

$\exists w_{4} \exists w_{5} \exists x_{2}\left(\left[\operatorname{Sister}\left(\mathrm{AR}, \dot{x}_{2}\right)\right]_{w_{4}} \wedge\left[\operatorname{Phil}\left(\dot{x}_{2}\right)\right]_{w_{4}} \wedge\left[\operatorname{Cellist}\left(\dot{x}_{2}\right)\right]_{w_{5}} \wedge\left[\neg \operatorname{Phil}\left(\dot{x}_{2}\right)\right]_{w_{5}}\right)$

(Read: there are admissible $a$-worlds $w_{4}$ and $w_{5}$ and an individual $x_{2}$ such that: $(i) x_{2}$ is used by $w_{4}$ to represent my sister and a philosopher, and (ii) $x_{2}$ is used by $w_{5}$ to represent a cellist rather than a philosopher.)

Finally, we show that there is a notion of $a$-world admissibility which guarantees that the actualist transformation of an arbitrary Lewisian sentence has the truth-value that the Lewisian sentence would receive on its intended interpretation. (The proof relies on the assumption that the Lewisian language is rich enough - and the space of Lewisian worlds varied enough with respect to predicates occurring in the language - that the set of true sentences has a model in which any two worlds are such that some atomic predicate is satisfied by a sequence of objects inhabiting one of the worlds, but not by the result of replacing each object in the sequence by its counterpart in the other world.) Start by enriching the Lewisian language with a standard name for each inhabitant of the actual world, and let $S$ be the set of true sentences in the extended language. One can use the Completeness Theorem to generate a model $M$ of $S$ in which the domain consists of " $=$ "-equivalence classes of terms and in which the assumption above is satisfied. If $a_{1}$ is an object in the individual-variable domain of $M$, let $a_{1}^{*}$ be the set of individuals $a_{2}$ such that " $\mathrm{C}\left(x_{1}, x_{2}\right)$ " is satisfied by $a_{1}$ and $a_{2}$. (I assume that " $\mathrm{C}$ " is an equivalence relation, and therefore that $*$ partitions the individual-variable domain of $M$ into equivalence classes.) If $a_{1}$ is an object in the individual-variable domain of $M$, let $a^{\dagger}$ be $\langle z$, "actual" $\rangle$ 
if the standard name of $z$ is in the transitive closure of $a^{*}$, and $\left\langle a^{*}\right.$, "nonactual" $\rangle$ otherwise.

For each $c$ in the world-variable domain of $M$, we construct an $a$-world $w_{c}$, as follows: the domain of $w_{c}$ is the set of $a^{\dagger}$ such that " $\mathrm{I}\left(x_{1}, w_{1}\right)$ " is satisfied by $a$ and $c$ in $M$; the $w_{c}$ extension of $\left\ulcorner\mathrm{P}_{j}^{n}\right\urcorner$ is the set of sequences $\left\langle a_{1}^{\dagger}, \ldots, a_{n}^{\dagger}\right\rangle$ such that " $\mathrm{I}\left(x_{1}, w_{1}\right) \wedge \ldots \wedge$ $\mathrm{I}\left(x_{n}, w_{1}\right) \wedge \mathrm{P}_{j}^{n}\left(x_{1} \ldots, x_{n}\right) "$ is satisfied by $a_{1}, \ldots, a_{n}, c$ in $M$. In addition we let individual constants receive their intended interpretations, and let " $\alpha$ " be $w_{c}$, where $c$ is the $M$-referent of " $\alpha$ ". Say that an $a$-world is admissible just in case it is a $w_{c}$ for some $c$ in the worldvariable domain of $M$. If $\sigma$ is a variable-assignment function in $M$, let $\sigma^{\dagger}$ be such that $\sigma^{\dagger}\left(\left\ulcorner x_{j}\right\urcorner\right)$ is $\sigma\left(\left\ulcorner x_{j}\right\urcorner\right)^{\dagger}, \sigma^{\dagger}\left(\left\ulcorner w_{j}\right\urcorner\right)$ is $w_{c}$ if $\left\ulcorner x_{j}\right\urcorner$ occurs in $\phi$ (where $c$ is such that " $\mathrm{I}\left(x_{1}, w_{1}\right)$ ") is satisfied by $\sigma\left(\left\ulcorner x_{j}\right\urcorner\right)$ and $c$ in $M)$, and $\sigma^{\dagger}\left(\left\ulcorner w_{j}\right\urcorner\right)$ is $w_{\sigma\left(\left\ulcorner w_{j}\right\urcorner\right)}$ if $\left\ulcorner x_{j}\right\urcorner$ does not occur in $\phi$. An induction on the complexity of formulas shows that a Lewisian formula $\phi$ is satisfied by an assignment function $\sigma$ in $M$ just in case the actualist transformation of its normal form is satisfied by $\sigma^{\dagger}$ when the worldvariables range over admissible $a$-worlds and the individual-variables range over the union of the domains of admissible $a$-worlds.

\section{REFERENCES}

Fine, K., 2005, Modality and Tense, Oxford University Press, Oxford.

- 2002, "The Problem of Possibilia", in Zimmerman 2002, pp. 161179. (Reprinted in Fine 2005, pp. 214-231.)

- 1994, "Essence and Modality", Philosophical Perspectives, vol. 8, pp. 1-16.

- 1985, "Plantinga on the Reduction of Possibilist Discourse", in Tomberlin and van Inwagen 1985, pp. 145-186. (Reprinted in Fine 2005, pp. 176-213.)

Heim, I., and A. Kratzer, 1998, Semantics in Generative Grammar, Blackwell, Oxford (Blackwell Textbooks in Linguistics).

Lewis, D., 1986, On the Plurality of Worlds, Blackwell, Oxford/New York. , 1983, Philosophical Papers, Volume I, Oxford University Press, Oxford.

— 1970, "General Semantics", Synthese, vol. 22, pp. 18-67. (Reprinted in Lewis 1983, pp. 189-229.)

— 1968, "Counterpart Theory and Quantified Modal Logic", The Journal of Philosophy, vol. 65, pp. 113-126. (Reprinted in Lewis 1983, pp. 26-39.)

Loux, M. (ed.), 1979, The Possible and the Actual, Cornell University Press, Ithaca. 
McMichael, A., 1983, "A Problem for Actualism about Possible Worlds", The Philosophical Review, vol. 92, pp. 49-66.

Melia, J., 2001, "Reducing Possibilities to Language", Analysis, vol. 61, pp. 19-29.

Peacocke, C., 1999, Being Known, Clarendon Press, Oxford.

Plantinga, A., 1976, "Actualism and Possible Worlds", Theoria, vol. 42, pp. 139-160. (Reprinted in Loux 1979, pp. 253-273.)

Rayo, A. (ed.) forthcoming, The Construction of Logical Space, Oxford University Press, Oxford.

Rayo, A., and G. Uzquiano, 1999, "Toward a Theory of Second-Order Consequence", The Notre Dame Journal of Formal Logic, vol. 40, pp. 315-325.

Roy, T., 1995, “On Defence of Linguistic Ersatzism”, Philosophical Studies, vol. 80, pp. 217-242.

Sider, T., 2002, "The Ersatz Pluriverse", Journal of Philosophy, vol. 99, pp. 279-315.

Stalnaker, R., 2012, "On What There Isn't (But Might Have Been)", Mere Possibilities: Metaphysical Foundations of Modal Semantics, Princeton University Press, Princeton, pp. 1-21.

Tomberlin, J., and P. van Inwagen (eds.), 1985, Alvin Plantinga, Reidel, Dordrecht (Reidel Profiles Series 5).

Williamson, T., 2010, “Necessitism, Contingentism, and Plural Quantification", Mind, vol. 119, pp. 657-748.

Zimmerman, D., 2002, Handbook of Metaphysics, Oxford University Press, Oxford.

Received: June 3, 2011; revised: June 14, 2012; accepted: July 25, 2012. 